\title{
Reduced second phase insulin secretion in carriers of a sulphonylurea receptor gene variant associating with Type II diabetes mellitus
}

\author{
L.M. 't Hart ${ }^{1}$, J.M. Dekker ${ }^{2}$, T. W. van Haeften ${ }^{3}$, J. B. Ruige ${ }^{2}$, C. D. A.Stehouwer ${ }^{2}$, D. W. Erkelens ${ }^{3}$, R. J.Heine ${ }^{2}$ \\ and J.A.Maassen ${ }^{1}$ \\ ${ }^{1}$ Leiden University Medical Centre, Department of Molecular Cell Biology, Leiden, The Netherlands \\ ${ }^{2}$ Institute for Research in Extramural Medicine, Vrije Universiteit Amsterdam, Amsterdam, The Netherlands \\ ${ }^{3}$ Department of Internal Medicine, Utrecht University, Utrecht, The Netherlands
}

\section{Abstract}

Aims/hypothesis. The sulphonylurea receptor is a subunit of the ATP-sensitive potassium channel in the pancreatic beta cell. Mutations at nt -3 of the splice acceptor site of exon 16 and a silent mutation in exon 18 of the gene for the sulphonylurea receptor (SUR1) associate with Type II (non-insulin-dependent) diabetes mellitus in several independent populations. We investigated whether these gene variants associate with changes in the pattern of glucose-stimulated insulin secretion.

Methods. Subjects who had normal glucose tolerance $(n=67)$ and subjects with an impaired glucose tolerance $(n=94)$, originating from two independent studies, were included in the study. Beta-cell function and insulin sensitivity were assessed by the hyperglycaemic clamp.

Results. Frequencies of the exon $16-3 t$ allele in the normal and impaired glucose tolerant groups were $46 \%$ and $44 \%$ respectively ( $p=\mathrm{NS})$. The more rare exon $18 \mathrm{~T}$ allele showed frequencies of 5 and $7 \%$ respectively $(p=\mathrm{NS})$. We observed an approximately $25 \%$ reduced second-phase insulin secretion in carriers of the exon $16-3 t$ allele in both groups $(p<0.05)$. Estimates of insulin sensitivity did not show differences between carriers and non-carriers. The variant in exon 18 and the combined presence of variants in exon 16 and exon 18 were not associated with differences in insulin secretion or insulin sensitivity in our study groups.

Conclusion/interpretation. The diabetes associated exon 16-3t variant of the SUR1 gene associates with a functional change of the beta cell as reflected by reduced second-phase insulin secretion in response to a standardized hyperglycaemia in normal and impaired glucose tolerant subjects. [Diabetologia (2000) 43: 515-519]

Keywords Type II diabetes mellitus, sulphonylurea receptor, genetics, insulin, beta cell, insulin secretion, impaired glucose tolerance, hyperglycaemic clamp.
The sulphonylurea receptor (SUR) is a subunit of the ATP-sensitive potassium channel $\left(\mathrm{K}_{\mathrm{ATP}}\right.$ channel) in the pancreatic beta cell $[1,2]$. The protein complex is involved in regulation of insulin secretion from the beta cell in response to glucose [1,2]. A mutation at

Received: 5 July 1999 and in revised form: 24 November 1999

Corresponding author: J.A. Maassen, Departent of Molecular Cell Biology, Leiden University Medical Centre, Wassenaarseweg 72, 2333 AL Leiden, The Netherlands

Abbreviations: SUR, Sulphonylurea receptor; ISI, insulin sensitivity index; MANOVA, multivariate analysis of variance; $\mathrm{K}_{\mathrm{ATP}}$ ATP-sensitive potassium channel. $\mathrm{nt}-3$ of the splice acceptor site of exon 16 and a silent mutation in exon 18 in the gene coding for the sulphonylurea receptor (SUR1) associate specifically with Type II (non-insulin-dependent) diabetes mellitus [3-5]. We recently showed the association between the exon $16-3 t$ allele and Type II diabetes mellitus in two cohorts from the Netherlands [6].

The mechanism underlying the association observed between SUR1 gene variants and Type II diabetes is not known but could be related to changes in the process of glucose-induced insulin secretion or peripheral glucose disposal. We assessed if there was any association between the two SURI gene variants and beta-cell function and insulin sensitivity as mea- 
Table 1. Clinical characteristics of the study groups

\begin{tabular}{lll}
\hline & NGT & IGT \\
\hline$n$ & 67 & 94 \\
Age (years) & $45.8 \pm 6.4$ & $57.0 \pm 7.3$ \\
BMI (kg/m $\left.{ }^{2}\right)$ & $25.8 \pm 3.7$ & $28.4 \pm 3.9$ \\
Sex $(\%$ men) & 29 & 48 \\
Waist:hip ratio & $0.81 \pm 0.07$ & $0.93 \pm 0.09$ \\
Fasting glucose (mmol/l) & $4.63 \pm 0.40$ & $6.56 \pm 0.56$ \\
Fasting insulin (pmol/l) & $30(24-42)$ & $66(47-97)$ \\
\hline
\end{tabular}

All values are expressed as means $( \pm \mathrm{SD})$ or medians (interquartile range)

sured by hyperglycaemic clamps. Two groups were studied, one with normal glucose tolerance and one with impaired glucose tolerance.

\section{Subjects and methods}

Normal glucose tolerant subjects. Subjects with normal glucose tolerance were in part recruited as first-degree offspring of Type II diabetic subjects $(n=44)$. The other part of the cohort consisted of matched normal glucose tolerant subjects without a family member known to have diabetes $(n=23)$ as described [7]. All participants underwent a $75 \mathrm{~g}$ oral glucose tolerance test (OGTT) to confirm normal glucose tolerance. Exclusion of two subjects with a first-degree relative within the study group had no effect on the observed associations.

Impaired glucose tolerant subjects. Subjects with IGT were selected from a random sample of subjects 45-74 years of age taken from the population registry of the town of Hoorn in the Netherlands. Participants $(n=94)$ were included when they had a mean postload glucose concentration between 8.6 and $11.1 \mathrm{mmol} / \mathrm{l}$ after two oral glucose tolerance tests [8]. For both study groups written informed consent was given by the participants and the study protocol was approved by the local medical ethics committee.

Hyperglycaemic clamp. A hyperglycaemic clamp was done at the individual research centres in Utrecht (NGT) and Hoorn (IGT) respectively [7-9]. Clamps were done in the fasting state, in the supine position. Baseline samples were drawn for plasma glucose and (pro)insulin determination. A priming infusion of glucose was then given to rapidly raise the blood glucose concentration to $10 \mathrm{mmol} / \mathrm{l}$. The blood glucose concentration was subsequently measured at 5-min intervals and was kept constant for $3 \mathrm{~h}$ at $10 \mathrm{mmol} / \mathrm{l}$ by variable glucose infusions. Samples for the determination of insulin were taken at 2 or 2.5 -min intervals during the first 10 minutes of the clamp; during the next $170 \mathrm{~min}$, samples were taken at 10 to 20-min intervals. Methods for the calculation of beta-cell function and estimates of insulin sensitivity under stable constant hyperglycaemia are explained in detail elsewhere $[7,8]$. Subjects with a second-phase insulin secretion less than 25 $\mathrm{pmol} / \mathrm{l}$ were excluded from calculations of the insulin sensitivity index (ISI) because these estimates might be unreliable as a result of a severely compromised beta-cell function $(n=3$ for the NGT group and $n=12$ for the IGT group, inclusion of these subjects in the analysis did not alter the results) $[10$, 11].
Biometry and laboratory analyses. Unfortunately our data do not allow comparison of the absolute concentrations of insulin between the NGT and IGT groups because different radioimmunoassays were used for the NGT (Utrecht) and IGT (Hoorn) groups [7, 8]. Proinsulin concentrations were not measured in the NGT group. All other relevant data were obtained using routine laboratory methods.

DNA analysis. We isolated DNA from peripheral blood and the two variants in the sulphonylurea receptor gene, at the -3 position in exon $16(c \rightarrow t)$ and in exon 18 at amino acid $\mathrm{Thr}^{759}$ $(\mathrm{ACC} \rightarrow \mathrm{ACT}$, silent), were detected by PCR-RFLP as described [6].

Statistical analysis. Data are presented as means $( \pm \mathrm{SD})$ or medians (interquartile range). We used ANOVA for general comparisons between the different groups. Multivariate analysis of variance (MANOVA) for repeated measures was used to test differences in insulin concentrations during the clamps between carriers and non-carriers of the two $S U R 1$ gene variants assuming a dominant effect of the exon $16-3 t$ allele. We used ANOVA when MANOVA for repeated measures showed statistically significant differences. Variables with a skewed distribution were log-transformed before analysis to normalise residuals. To adjust for the influence of age, BMI and sex, on all associations separate analyses were done including these variables. Results were regarded significant at $p$ of 0.05 or less. Analysis were done with the SPSS 7.0 software (Chicago, Il., USA).

\section{Results}

A normal group and one with impaired glucose tolerance were included in our study. Characteristics of the two study groups are given in Table 1 . In the NGT group, the distribution of the exon 16 genotype was: $31 \%$ for the $-3 c / c$ genotype $(n=21), 46 \%$ for the $-3 c / t$ genotype $(n=31)$ and $22 \%$ for the $-3 t / t$ genotype $(n=15)$. The frequency of the $-3 t$ allele was higher in the subjects with a diabetic relative compared with those without, but the difference was not significant (allele frequency $49 \%$ vs $39 \%$, $p=0.28)$. Of the subjects seven $(11 \%)$ were heterozygous carriers of the exon 18 variant and three of them had also the exon 16 variant $(5 \%)$. In the IGT group, the prevalences of the different exon 16 genotypes was $33 \%$ for the $-3 c / c$ genotype $(n=31)$, $46 \%$ for the $-3 c / t$ genotype $(n=43)$ and $21 \%$ for the $-3 t / t$ genotype $(n=20)$, respectively. The exon $16-3 t$ allele frequency was $44 \%$. The exon 18 gene variant was found in heterozygous form in $15 \%$ of the subjects $(n=14)$; homozygous carriers of this mutation were not found. Of the subjects $12 \%(n=11)$ had mutations in both exons (either exon $16-3 c / t$ or $-3 t / t$ genotype and exon $18 \mathrm{C} / \mathrm{T}$ genotype). The genotype distributions between both groups were not significantly different.

Carriers of the exon $18 \mathrm{C} / \mathrm{T}$ genotype or the combined exon $16(-3 c / t$ or $-3 t / t) /$ exon $18 \mathrm{C} / \mathrm{T}$ genotype were clinically indistinguishable from carriers of the 

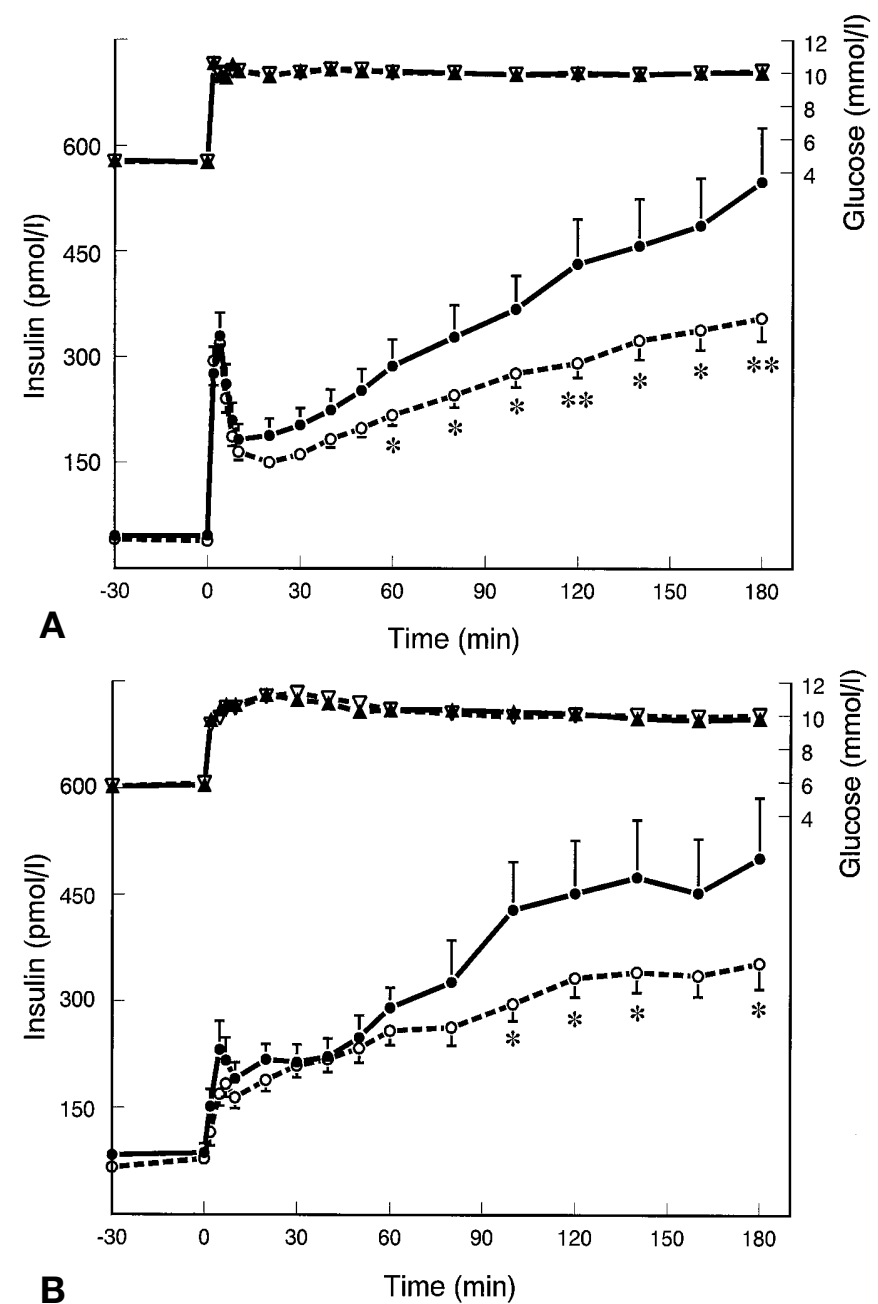

Fig. 1A,B. Glucose and insulin profiles during a hyperglycaemic clamp for $3 \mathrm{~h}$ at $10 \mathrm{mmol} / \mathrm{l}$ glucose according to the presence of the exon $16-3 t$ allele. Data are expressed as means $( \pm$ SEM). A Subjects with NGT $(n=67)$. B Subjects with IGT $(n=94)$. and $\boldsymbol{\Delta}$, Carriers of two exon $16-3 c / c$ alleles, $\bigcirc$ and $\nabla$, carriers of the $-3 t$ allele on one or both alleles. Circles represent insulin profiles and triangles represent glucose profiles respectively. $* p \leq 0.05, * * p \leq 0.01$

wild-type genotypes in both the NGT and IGT group in all variables tested (data not shown).

Results for the exon $16-3 t$ indicated the absence of a gene dose effect of the $-3 t$ allele in either of the two groups. Therefore a model with a dominant effect of the exon $16-3 t$ allele was used in all analyses (e.g. $-3 c / c$ vs $-3 c / t$ and $-3 t / t)$.

Beta cell function in carriers of the exon 16-3t allele. In the NGT group, we noted that carriers of the $-3 t$ allele had a lower (second-phase) insulin secretion compared with carriers of two $-3 c$ alleles (Fig. 1A). The MANOVA for repeated measures showed a significantly reduced insulin secretion during the last hour of the clamp in carriers of the exon $16-3 t$ allele, $p=0.013$. A separate ANOVA showed significant differences in plasma insulin concentrations during the clamp at all time points from 60 min onwards (all $p<0.05$, Fig. $1 \mathrm{a}$ ). The second-phase insulin secretion, calculated as the average of the last three time points minus basal, in the carriers of the $-3 t$ allele was 300 (228-384) pmol/l compared with 396 (246-714) $\mathrm{pmol} / \mathrm{l}$ in carriers of two $-3 c$ alleles, $p=0.02$ (Table 2). Correction for the influence of age, BMI and sex reduced the observed association slightly $(p=0.07)$. This association was independent of a family history of Type II diabetes. First-phase insulin secretion, insulin sensitivity (ISI, as measured with the glucose clamp) and fasting insulin were similar between carriers and non-carriers (Table 2).

In the IGT group we also observed lower insulin secretion profiles in carriers of the $-3 t$ allele during the hyperglycaemic clamp (Fig. 1b). In this group MANOVA for repeated measures also showed significantly lower insulin secretion during the last hour of the clamp, $p=0.05$. Subsequent ANOVA showed significantly different plasma insulin concentrations between carriers and non-carriers at all time points from $100 \mathrm{~min}$ onwards $(\mathrm{p} \leq 0.05)$ except at $160 \mathrm{~min}$ $(p=0.09)$. Carriers and non-carriers had a secondphase insulin secretion of $210(114-360)$ and 288 (162-504) pmol/l, respectively, $p=0.06$ (Table 2). After correction for age, BMI and sex this association became statistically significant, $p=0.05$. The fasting proinsulin: specific-insulin ratio was significantly increased in carriers of the exon 16-3t allele compared with the $-3 c / c$ genotype in this group [0.09 (0.06-0.11) vs $0.07(0.05-0.09), p=0.05]$. The association was slightly decreased by correction for age, sex and BMI $(p=0.07)$. The IGT carriers of the $-3 t$ allele also tended to have a lower first-phase insulin response but this was not significantly different [Fig. 1 b, 558 (198-1068) versus 816 (294-1134) pmol/l, $p=0.18]$. The ISI and fasting insulin concentrations were not different (Table 2).

Clinical variables. There were no statistically significant differences in other clinical characteristics like age, BMI, waist-to-hip ratio, sex, $\mathrm{HbA}_{1 \mathrm{c}}$ and lipids between carriers of the different exon 16 genotypes (data not shown).

\section{Discussion}

We previously reported that the presence of the exon $16-3 t$ allele of the $S U R 1$ gene represents a risk factor for the development of Type II diabetes mellitus in the Netherlands [6]. The present study provides evidence for an association between the exon $16-3 t$ allele and a reduced insulin secretion during the second-phase in response to a standardized glucose stimulus. This defect was observed both in subjects with NGT and IGT. 
Table 2. Hyperglycaemic clamp results in NGT and IGT subjects according to SUR1 exon 16 (nt -3) genotype

\begin{tabular}{|c|c|c|c|c|c|c|}
\hline & \multicolumn{3}{|l|}{ NGT } & \multicolumn{3}{|l|}{ IGT } \\
\hline & \multicolumn{3}{|c|}{ Exon $16(n t-3)$ genotype } & \multicolumn{3}{|c|}{ Exon $16(\mathrm{nt}-3)$ genotype } \\
\hline & $-3 c / c$ & $-3 c / t+-3 t / t$ & $p$ value & $-3 c / c$ & $-3 c / t+-3 t / t$ & $p$ value \\
\hline Fasting insulin (pmol/l) & $36(2454)$ & $30(2442)$ & 0.11 & $70(54106)$ & $66(4594)$ & 0.49 \\
\hline $\begin{array}{l}\text { Fasting intact } \\
\text { proinsulin }(\mathrm{pmol} / \mathrm{l})\end{array}$ & n. a. & n. a. & & $3.5(1.95 .8)$ & $4.9(3.07 .3)$ & 0.13 \\
\hline $\mathrm{M}\left(\mathrm{mg} / \mathrm{kg} \mathrm{min} \mathrm{mi}^{-1}\right)$ & $10.9(7.814 .0)$ & $8.8(6.712 .3)$ & 0.17 & $5.4(4.46 .6)$ & $5.0(3.66 .7)$ & 0.30 \\
\hline $1^{\text {st }}$-phase ins. secr. (pmol/l) & 1914 (1008 2484) & 1548 (1188 2340) & 0.94 & $816(2941134)$ & $558(1981068)$ & 0.18 \\
\hline $2^{\text {nd }}-$ phase ins. secr. $(\mathrm{pmol} / \mathrm{l})$ & $396(246714)$ & $300(228384)$ & 0.02 & $288(162504)$ & $210(114360)$ & 0.06 \\
\hline $\begin{array}{l}\text { Ins. sensitivity } \\
100^{*}\left(\mathrm{mg} \cdot \mathrm{kg}^{-1} \cdot \mathrm{min}^{-1} \cdot \mathrm{pmol} \cdot \mathrm{l}^{-1}\right)\end{array}$ & $3.3(1.84 .5)$ & $3.1(2.14 .6)$ & 0.33 & $1.5(0.92 .6)$ & $1.4(1.02 .1)$ & 0.93 \\
\hline
\end{tabular}

All values are expressed as medians (interquartile range). n. a. not available. Difference between wild-type and mutant genotypes was tested by analysis of variance, variables with a skewed distribution were log transformed before analysis of variance

The observed genotype frequencies in both groups are similar to the frequencies we previously reported in the Netherlands, which argues against a large bias introduced by the selection of the study subjects [6]. As long as there is no evidence for SUR1 dysfunction in carriers of this gene variant the possibility of genetic admixture or population stratification cannot be excluded [12]. Our independent results in three different populations makes, however, this hypothesis unlikely.

In the high risk IGT group we observed, apart from the reduced second-phase insulin secretion, also a slightly reduced first-phase insulin secretion in carriers of the $-3 t$ allele. Furthermore, we observed a significantly higher proinsulin:specific-insulin ratio. Both a reduced first-phase insulin secretion and increased proinsulin:specific-insulin ratio are risk indicators for the development of Type II diabetes [13-16]. Previously it has been shown that NGT subjects with a first-degree Type II relative and IGT subjects both show defects in first-phase and secondphase insulin response $[17,18]$. Prospective studies will be needed to evaluate whether those subjects with the exon 16-3t allele will develop Type II diabetes more often compared with the carriers of the $-3 c$ allele. In combination with monitoring beta-cell function in these subjects upon follow-up this would also provide insight into the importance of the decrease observed in second-phase insulin secretion on the development of Type II diabetes.

Insulin sensitivity (ISI), being another important factor in the development of Type II diabetes [13], was estimated using the data from the hyperglycaemic clamps. It has been shown that ISI, as assessed during hyperglycaemic clamps, correlates quite well with ISI as assessed using the euglycaemic-hyperinsulinaemic clamp in both NGT $[9,11]$ and IGT subjects
$[10,19]$. Insulin sensitivity was not significantly different between carriers of the different exon 16 alleles in both the NGT and IGT groups. This observation underlines that the gene variant directly affects the beta cell rather than insulin sensitivity. Our results agree with another study in which changes were also observed in beta-cell function, as reflected by an attenuated tolbutamide-induced insulin secretion, in normo-glycaemic carriers of SUR1 gene variants [5]. Likewise in that study no change in insulin sensitivity was observed.

The changes in insulin secretion seen in our subjects could result from functional changes in the pancreatic $\mathrm{K}_{\mathrm{ATP}}$ channel, as this channel is an important regulator of insulin secretion [2]. Although the exon $16-3 t$ variant is not located in the coding region, it might affect mRNA (expression) by changes in the efficiency of the splicing process or stability of the primary transcript. Analysis of SUR1 mRNA in pancreatic tissue should provide insight in the splicing patterns in carriers of the $-3 c$ allele and $-3 t$ allele, respectively.

We conclude that the exon $16-3 t$ variant of the SUR1 gene is associated with beta-cell dysfunction in both subjects with normal and impaired glucose tolerance.

Acknowledgements. The authors would like to thank the participants for their cooperation. This work was supported by grants from the Diabetes Fonds Netherland and the European Economic Community (BMH4-CT-98-3084). 


\section{References}

1. Aguilar-Bryan L, Clement JP, Gonzalez G, Kunjilwar K, Babenko A, Bryan J (1998) Toward understanding the assembly and structure of K-ATP channels. Physiol Rev 78: 227-245

2. Miki T, Nagashima K, Seino S (1999) The structure and function of the ATP-sensitive $\mathrm{K}+$ channel in insulin-secreting pancreatic beta-cells. J Mol Endocrinol 22: 113-123

3. Inoue H, Ferrer J, Welling CM et al. (1996) Sequence variants in the sulfonylurea receptor (SUR) gene are associated with NIDDM in caucasians. Diabetes 45: 825-831

4. Hani E, Clement K, Velho G et al. (1997) Genetic studies of the sulfonylurea receptor gene locus in NIDDM and in morbid obesity among French caucasians. Diabetes 46: 688-694

5. Hansen T, Echwald SM, Hansen L et al. (1998) Decreased tolbutamide-stimulated insulin secretion in healthy subjects with sequence variants in the high- affinity sulfonylurea receptor gene. Diabetes 47: 598-605

6. 't Hart LM, De Knijff P, Dekker JM et al. (1999) Variants in the sulphonylurea receptor gene:association of the exon $16-3 t$ variant with Type II diabetes mellitus in the Netherlands. Diabetologia 42: 617-620

7. Van Haeften TW, Zonderland ML, Dubbeldam S, Erkelens DW (1998) Insulin secretion in normal glucose-tolerant relatives of type 2 diabetic subjects. Assessments using hyperglycemic glucose clamps and oral glucose tolerance tests. Diabetes Care 21: 278-282

8. Ruige JB, Dekker JM, Nijpels G et al. (1999) Hyperproinsulinaemia in impaired glucose tolerance is associated with a delayed insulin response to glucose. Diabetologia 42: $177-180$

9. Defronzo RA, Tobin JD, Andres R (1979) Glucose clamp technique:a method for quantifying insulin secretion and resistance. Am J Physiol-Endocrinol Met 237:E214-E223

10. Ruige JB (1998) An epidemiological approach to the pathogenesis of diabetes mellitus (Thesis). Vrije Universiteit Amsterdam
11. Mitrakou A, Vuorinen-Markkola H, Raptis G et al. (1992) Simultaneous Assessment of insulin secretion and insulin sensitivity using a hyperglycemic clamp. J Clin Endocrinol Metab 75: 379-382

12. Altshuler D, Kruglyak L, Lander E (1998) Genetic polymorphisms and disease. N Engl J Med 338: 1626

13. Defronzo RA (1997) Pathogenesis of type 2 diabetes:metabolic and molecular implications for identifying diabetes genes. Diabetes reviews 5: 177-285

14. Nijpels G, Popp-Snijders C, Kostense PJ, Bouter LM, Heine RJ (1996) Fasting proinsulin and 2-h post-load glucose levels predict the conversion to NIDDM in subjects with impaired glucose tolerance:The Hoorn Study. Diabetologia 39: $113-118$

15. Mykkanen L, Haffner SM, Hales CN, Ronnemaa T, Laakso M (1997) The relation of proinsulin, insulin, and proinsulin-to-insulin ratio to insulin sensitivity and acute insulin response in normoglycemic subjects. Diabetes 46: 1990-1995

16. Roder ME, Porte D, Schwartz RS, Kahn SE (1998) Disproportionately elevated proinsulin levels reflect the degree of impaired B cell secretory capacity in patients with noninsulin-dependent diabetes mellitus. J Clin Endocrinol Metab 83: 604-608

17. Pimenta W, Korytkowski M, Mitrakou A et al. (1995) Pancreatic beta-cell dysfunction as the primary genetic lesion in NIDDM. Evidence from studies in normal glucose-tolerant individuals with a first-degree NIDDM relative. JAMA 273: 1855-1861

18. Van Haeften TW, Pimenta W, Mitrakou A et al. (1999) Contributions of family history of diabetes to beta cell function and insulin sensitivity in IGT. Diabetes 48 [Suppl 1] 1929 (abstract)

19. Pimenta W, Mitrakou A, Jensen T, Yki-Jarvinen H, Daily G, Gerich J (1996) Insulin secretion and insulin sensitivity in people with impaired glucose tolerance. Diabetic Med 13: S33-S36 